\title{
Sample preparation method for metal(loid) contaminant quantitation in rodent hair collected in Yuma County, Arizona
}

\author{
Jonathan Credo (iD) Amy Chandos • \\ Camilla Checinski • Frank A. von Hippel • \\ Jani C. Ingram
}

Received: 17 February 2021 / Accepted: 12 July 2021 / Published online: 27 July 2021

(C) The Author(s) 2021

\begin{abstract}
Yuma County, Arizona, is a large agricultural hub of the USA located in the southwestern corner of Arizona on the USA-Mexico border. Yearround use of agrichemicals at a massive scale along with the influx of aquatic contaminants in the Colorado River led to significant levels of environmental pollution and hence exposure risks for people and wildlife. Although hair is a recognized biomarker for metal exposure, there is no universal hair preparation protocol. This study evaluated two digestion methods for metal quantitation using inductively coupled plasma-mass spectrometry (ICP-MS) and three methods for mercury quantitation using cold vapor-atomic absorption spectroscopy (CV-AAS), both employing certified reference materials. The "overnight" and "heating" digestion methods were suitable for
\end{abstract}

J. Credo $(\bowtie)$

College of Medicine, University of Arizona, Tucson, AZ, USA

e-mail: jmcredo@email.arizona.edu

A. Chandos

Department of Biological Sciences, Northern Arizona

University, Flagstaff, AZ, USA

C. Checinski $\cdot$ J. C. Ingram

Department of Chemistry \& Biochemistry, Northern

Arizona University, Flagstaff, AZ, USA

F. von Hippel

Community, Environment and Policy, Mel and Enid

Zuckerman College of Public Health, University

of Arizona, Tucson, AZ, USA
ICP-MS, while only the heating method was suitable for CV-AAS. These validated methods will be useful for a variety of human and wildlife assessments of toxic metal(loid) exposure.

Keywords ICP-MS · CV-AAS · Agrichemical exposure $\cdot$ Sample preparation $\cdot$ Rodent animal model

\section{Introduction}

Yuma County, Arizona, is an important agricultural region of the USA as it provides more than $90 \%$ of leafy greens consumed in the USA during winter, in addition to many other crops (Kerna \& Frisvold, 2014). To maintain high agricultural yields, more than 2.6 million kilograms of organic and inorganic based pesticides is applied to fields each year (Sugeng et al., 2013). Pesticide exposure represents a significant health concern for humans and wildlife due to the heavy use in Yuma County, application techniques, and wind patterns that mobilize pesticides across the region. A myriad of detrimental health effects is linked to pesticide exposure, which depend on the length and dose of the exposure along with the type of pesticide (Alavanja et al., 2004; Baldi et al., 2011; Lizardi et al., 2008). Lizardi et al. (2008) evaluated the neurobehavioral performance of Hispanic children from Yuma County and other southern Arizona agricultural communities and demonstrated that exposure to organophosphate pesticides led to deleterious mental functioning and performance. To date, studies 
conducted in Yuma County have focused on organic pesticide exposure, leaving a knowledge gap on the effects of inorganic pesticides on the population and environment (Lizardi et al., 2008; Sugeng et al., 2013).

In this paper, we evaluate three digestion protocols for the quantitation of toxic metal(loid)s in rodent hair to validate these methods for studies of human and wildlife health effects due to exposure. Several toxic metal(loid)s are active ingredients of historically used inorganic pesticides (lead $(\mathrm{Pb})$, mercury $(\mathrm{Hg})$, arsenic (As)), while others are still used in agriculture (manganese (Mn), copper (Cu)) (Sugeng et al., 2013). Furthermore, many other sources of exposure to toxic metal(loid)s exist in Yuma County and throughout the world. Hair was chosen because it represents a non-invasive and easy-to-gather biomarker for exposure that has been used to assess body burden (Gellein et al., 2008; Pirrone et al., 2013). Animal keratin, including rodent hair, is frequently used to assess exposure burden (Appenzeller et al., 2017; Beernaert et al., 2007; Jaspers et al., 2019; Lettoof et al., 2021). Unfortunately, some metals used in inorganic pesticides have not been sufficiently studied in hair, and there is a lack of consensus on hair preparation and digestion methods (Ishak et al., 2015; Pozebon et al., 2017). This is exemplified by the meta-analysis conducted by Pozebon et al. (2017), which reviewed the current literature for hair preparation and digestion protocols. Protocols were evaluated using certified reference materials (CRMs) and selected based upon feasibility given small sample masses of hair. The goal is to determine the most efficacious method for analysis of toxic metal(loid)s in hair samples from rodents collected in Yuma County, and more generally for similar studies elsewhere.

\section{Materials and methods}

\section{Rodent sample collection}

Rodents were collected using Sherman live traps, baited with peanut butter and birdseed, at seven sites across Yuma County, from November 2018 through November 2019. Rodents were captured in riparian areas adjacent to agricultural lands and the Colorado River within the municipalities of Yuma and Somerton, as well as at our reference site at Mittry
Lake, a natural wetlands area fed by the Colorado River located $20 \mathrm{~km}$ north of Yuma and $15 \mathrm{~km}$ upstream from the nearest agriculture (Fig. 1). Traps were placed at sampling locations at dusk, and then checked the following morning at dawn. Male and female adult rodents were kept, and juveniles were released. Captured rodents were either transported to the lab at the NAU Yuma campus or field dissected. All rodents were humanely euthanized following established American Veterinary Medical Association procedures using isoflurane (Underwood \& Anthony, 2020). Morphological characteristics (e.g., species identification, body length, body weight, sex) were recorded prior to hair being collected from their dorsum. Hair was shaved with a trimmer, which was sterilized between animals. Additional tissue samples were collected (e.g., blood, gonads, thyroid) for separate histological, endocrinological, and gene expression assays to be reported elsewhere. Hair was placed in envelopes, given an alphanumeric code, and transported to NAU Flagstaff for preparation and analysis. Of the species captured, only Peromyscus eremicus (cactus mouse) hair was used in the current study because they were the most abundant. Rodent collection was approved by the Northern Arizona University (NAU) Institutional Animal Care and Use Committee (protocol 17-013) and the Arizona Department of Game and Fish (Licenses SP611340 \& SP639726).

Instrumentation and method validation

All analyses were conducted at the NAU Flagstaff campus. Total $\mathrm{Hg}$ was quantified using a PerkinElmer FIMS 100 CV-AAS with a PerkinElmer S10 Autosampler, and elemental analysis (As, cadmium $(\mathrm{Cd}), \mathrm{Cu}$, and $\mathrm{Pb}$ ) was accomplished using a Thermo $\mathrm{X}$ Series II ICP-MS with standard glass spray chamber introduction. Standard operating parameters were used for the FIMS 100 (EPA, 2007a; McIntosh, 1993). Prior to each analysis, the ICP-MS was tuned using Tune Solution A (Inorganic Ventures). ERM-DB001 Human hair (trace elements, from the European Commission Joint Research Centre) and NIST 1640a (trace elements in natural water, from the National Institute of Standards and Technology) CRMs were used to assess digestion and instrument efficiency. Rhodium (Rh) and iridium (Ir) at $1.00 \mu \mathrm{g} / \mathrm{L}$ were used as internal standards for ICP-MS analysis. 


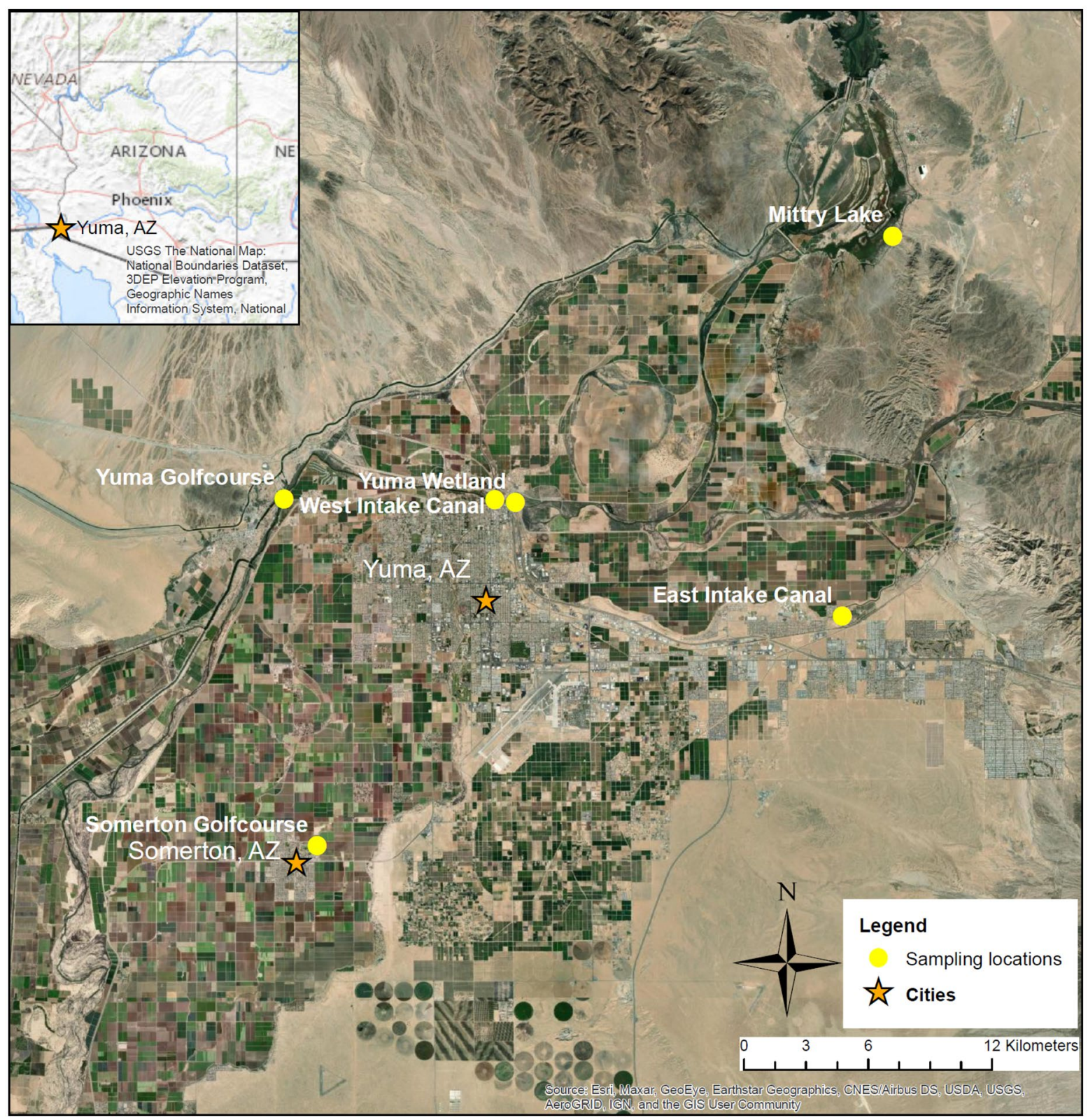

Fig. 1 Study region in Yuma County, Arizona. Rodent collection sites are denoted by yellow circles. Map insert shows location of Yuma County, AZ

\section{Digestion methodology}

Three digestion methods were adapted from previously published protocols and performed using hair from one of three rodents (YG10, YG12, YG14): (1) heating, (2) overnight, and (3) potassium permanganate $\left(\mathrm{KMnO}_{4}\right.$; Table 1) (Ishak et al., 2015; Pozebon et al., 2017). For each method, the digestion efficiency was evaluated with a CRM (ERM-DB001 Human Hair, washed and powdered) (Astolfi et al., 2020; Cabral Pinto et al., 2019). All three digestion methods were evaluated for total $\mathrm{Hg}$ quantitation (Fig. 2). For the heating method, hair samples (30-40 mg) were digested with $1400 \mu \mathrm{L}$ trace metal clean concentrated hydrochloric acid ( $\mathrm{HCl}$; 35\%; Fisher Chemical) and $75 \mu \mathrm{L}$ suprapur 
Table 1 Summary of the three hair digestion methods used for $\mathrm{Hg}$ analysis by a Perkin-Elmer FIMS $100 \mathrm{CV}-\mathrm{AAS}$

\begin{tabular}{|c|c|c|c|c|}
\hline Protocol name & $\begin{array}{l}\text { Sample } \\
\text { weight } \\
(\mathrm{mg})\end{array}$ & Chemical digest & Heating & Dilution and filtration \\
\hline Heating & $30-40$ & $1400 \mu \mathrm{L} \mathrm{HCl}+75 \mu \mathrm{L} \mathrm{H}_{2} \mathrm{O}_{2}$ & $90 \min 100^{\circ} \mathrm{C}$ isotherm & $\begin{array}{l}\text { Diluted to } 15 \mathrm{~mL} \text { with } \mathrm{NP} \text {, } \\
\text { filtered }\end{array}$ \\
\hline Overnight & $30-40$ & $1400 \mu \mathrm{L} \mathrm{HCl}+75 \mu \mathrm{L} \mathrm{H}_{2} \mathrm{O}_{2}$ & $\begin{array}{l}12 \text { h overnight } \\
\text { digest }+90 \min 100{ }^{\circ} \mathrm{C} \\
\text { isotherm }\end{array}$ & $\begin{array}{l}\text { Diluted to } 15 \mathrm{~mL} \text { with NP, } \\
\text { filtered }\end{array}$ \\
\hline Potassium Permanganate & 500 & $\begin{array}{l}5 \mathrm{~mL} \mathrm{HCl}, 2 \mathrm{~mL} 5 \%(\mathrm{w} / \mathrm{v}) \\
\mathrm{KMnO}_{4}, 30 \mathrm{~mL} \text { distilled } \\
\text { water }\end{array}$ & $\begin{array}{l}24 \mathrm{~h} \text { digest }+120 \mathrm{~min} 80^{\circ} \mathrm{C} \\
\text { water bath }\end{array}$ & $\begin{array}{l}\text { Diluted to } 50 \mathrm{~mL} \text { with distilled } \\
\text { water, filtered, } 5 \text { drops } 10 \% \\
\text { hydroxylamine and antifoam- } \\
\text { ing agent }\end{array}$ \\
\hline
\end{tabular}

hydrogen peroxide $\left(\mathrm{H}_{2} \mathrm{O}_{2} ; 30 \%\right.$; Sigma-Aldrich), and placed in a $100{ }^{\circ} \mathrm{C}$ isotherm for $90 \mathrm{~min}$. Prior to analysis, samples were diluted to $15 \mathrm{~mL}$ with nanopure water (NP) and filtered with Whatman GD/X PVDF $0.45-\mu \mathrm{m}$ syringe filters. For the overnight method, the same protocol for heating was followed with the addition of a $12 \mathrm{~h}$ overnight digest (also in $1,400 \mu \mathrm{L} \mathrm{HCl}$ and $75 \mu \mathrm{L} \mathrm{H}_{2} \mathrm{O}_{2}$ ) prior to samples being placed in the isotherm. For the potassium permanganate method, samples of hair $(500 \mathrm{mg})$ were digested with $5 \mathrm{~mL} \mathrm{HCl}, 2 \mathrm{~mL} 5 \%(\mathrm{w} / \mathrm{v}) \mathrm{KMnO}_{4}$ (Acros Chemical), and $30 \mathrm{~mL}$ of distilled water. Samples were digested for $24 \mathrm{~h}$ and then placed into an $80{ }^{\circ} \mathrm{C}$ water bath for $2 \mathrm{~h}$. After digestion,

Fig. 2 Comparison of the effect of washing rodent hair samples on $\mathrm{Hg}$ concentration as evaluated by CV-AAS. Samples labeled "UW" represent unwashed hair samples and samples labeled "W" represent washed hair samples. The legend at the bottom denotes the different digestion method (left to right_-"heating," "overnight," "potassium permanganate"). Standard deviation is represented as capped bars for each sample

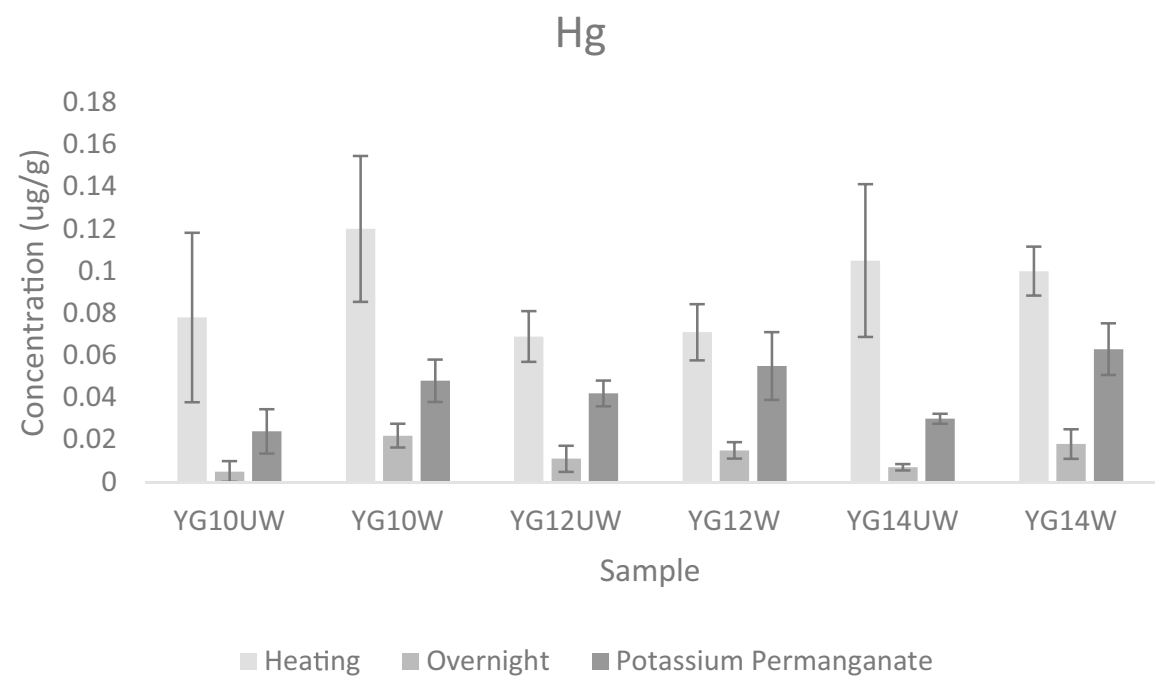

Table 2 Summary of the two hair digestion methods used for elemental analysis by a Thermo-Fisher X-Series II ICP-MS

\begin{tabular}{lllll}
\hline Protocol name & Sample weight $(\mathrm{mg})$ & Chemical digest & Heating & Dilution and filtration \\
\hline Heating & $30-40 \& 200$ & $1500 \mu \mathrm{L} \mathrm{HNO}_{3}+80 \mu \mathrm{L} \mathrm{H}_{2} \mathrm{O}_{2}$ & 90 min $100{ }^{\circ} \mathrm{C}$ isotherm \\
Overnight & $30-40 \& 200$ & $1500 \mu \mathrm{LNO}_{3}+80 \mu \mathrm{L} \mathrm{H}_{2} \mathrm{O}_{2}$ & $\begin{array}{c}12 \text { h overnight } \\
\text { digest }+90 \mathrm{~min} 100{ }^{\circ} \mathrm{C}\end{array}$ & Diluted to $15 \mathrm{~mL}$ with NP, filtered \\
& & & isotherm & Diluted to $15 \mathrm{~mL}$ with $\mathrm{NP}$, filtered \\
& & &
\end{tabular}


Fig. 3 Comparison of effect of hair washing on rodent hair samples as evaluated by ICP-MS. Both the heating and overnight digestion methods were compared again, because both had comparable recoveries for ICP-MS analysis on washed samples. Samples labeled "UW" represent unwashed hair samples and samples labeled "W" represent washed hair samples. The legend at the bottom denotes the different digestion method (left is heating and right is overnight). Standard deviation is represented as capped bars for each sample

samples were diluted to a final volume of $50 \mathrm{~mL}$, filtered (VWR qualitative $33 \mathrm{~cm}$ filter paper), and the $\mathrm{KMnO}_{4}$ was neutralized with $10 \%$ hydroxylamine (Fisher Chemical) and two-three drops of XIAMETER AFE-0110 Antifoam Emusion added (Dow Chemical).

The heating and overnight digestion methods were also evaluated by ICP-MS and utilized the same rodent hair samples (YG10, YG12, YG14) (Table 2; Fig. 3). For the heating method, samples of hair (20 mg and $200 \mathrm{mg}$ ) were digested with 1500 $\mu \mathrm{L}$ of OPTIMA grade nitric acid (Fisher Chemical) and $80 \mu \mathrm{L} \mathrm{H}_{2} \mathrm{O}_{2}$, and placed into a $100{ }^{\circ} \mathrm{C}$ isotherm for $90 \mathrm{~min}$. After digestion, samples were diluted to $15 \mathrm{~mL}$ with NP and filtered. For the overnight method, the same protocol for heating was followed with the addition of a $12 \mathrm{~h}$ overnight digest prior to samples being placed in the isotherm.

\section{Hair washing}

The impact of hair washing was evaluated on three rodent samples using a modified International Atomic Energy Agency protocol (Pozebon et al., 2017). Hair samples were washed with acetone (CHROMASOLV for HPLC $>99.8 \%$, Sigma Aldrich), rinsed three times with NP water, and rinsed with acetone again, and then 20-40 mg of washed and unwashed sample was digested by the methods above and analyzed by ICP-MS and CV-AAS.

\section{Results and discussion}

Comparison of the three digestion methods for CVAAS showed that all three methods resulted in $\mathrm{Hg}$ values lower than the expected value based on the CRM (Table 1). This is expected due to the high volatility of $\mathrm{Hg}$. Of the three methods, the heating method resulted in the only accuracy that fell within
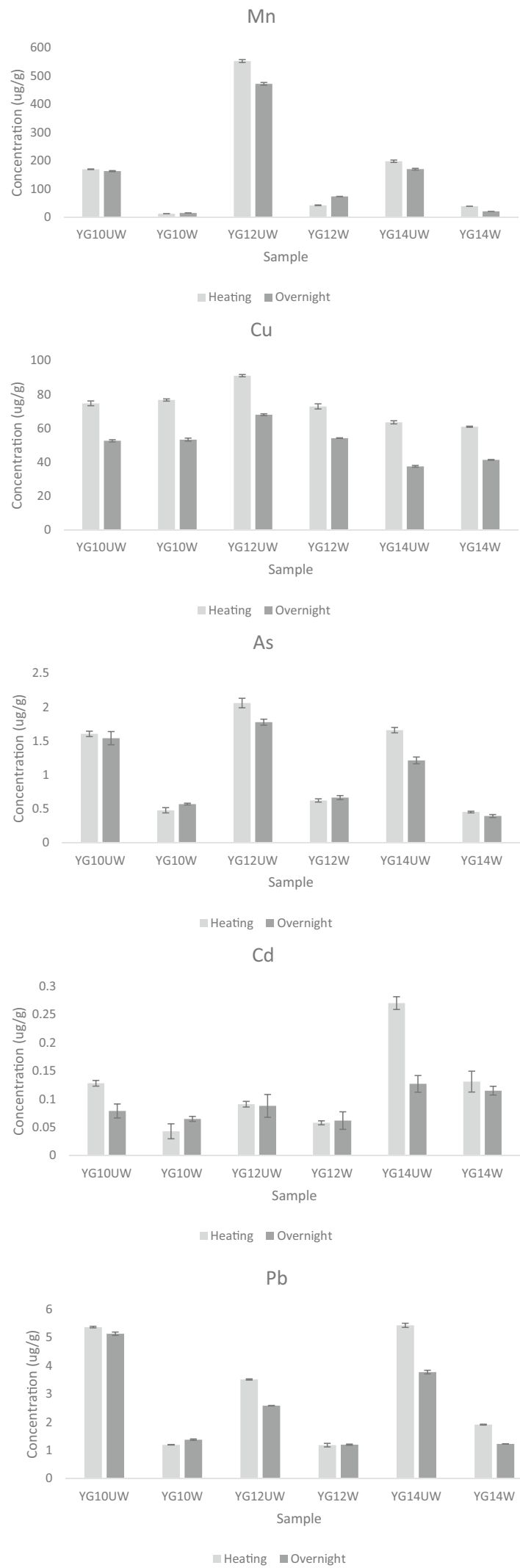
Table 3 Comparison of the two digestion methods, each with two approximate masses of CRM used, evaluated by ICP-MS. The elements and isotopes compared are displayed at the top of table. The second row shows the true reported value and uncertainty, 95\% confidence with coverage factor $k=2$, of the $\mathrm{CRM}$ in $\mu \mathrm{g} / \mathrm{g}$. This is followed by the digestion method average reported value in $\mu \mathrm{g} / \mathrm{g}$. The final rows show percent error based on the reported value compared to the true value

\begin{tabular}{llllllll}
\hline & Element & $65 \mathrm{Cu}$ & $75 \mathrm{As}$ & $111 \mathrm{Cd}$ & $206 \mathrm{~Pb}$ & $207 \mathrm{~Pb}$ & $208 \mathrm{~Pb}$ \\
\hline & $\begin{array}{l}\text { True }(\mu \mathrm{g} / \mathrm{g})(\text { uncer- } \\
\text { tainty) }\end{array}$ & $33(4)$ & $0.044(0.006)$ & $0.125(0.007)$ & $2.14(0.20)$ & $2.14(0.20)$ & $2.14(0.20)$ \\
& Overnight 20 mg & 33.481 & 0.036 & 0.105 & 2.045 & 2.133 & 2.091 \\
$\begin{array}{c}\text { Method average } \\
(\mu \mathrm{g} / \mathrm{g})\end{array}$ & Overnight 200 mg & 20.800 & 0.025 & 0.063 & 1.554 & 1.624 & 1.597 \\
& Heating 20 mg & 31.602 & 0.038 & 0.105 & 3.885 & 4.067 & 3.991 \\
& Heating 200 mg & 18.929 & 0.023 & 0.066 & 1.577 & 1.652 & 1.624 \\
Method percent & Overnight 20 mg & $9.51-15.45$ & $4.08-27.10$ & $11.23-20.65$ & $5.41-12.61$ & $8.86-9.93$ & $7.76-10.66$ \\
error (\%) & Overnight 200 mg & $28.28-43.78$ & $35.27-50.81$ & $46.33-52.02$ & $19.89-33.58$ & $16.31-30.62$ & $17.68-31.75$ \\
& Heating 20 mg & $8.97-14.59$ & $0.40-23.69$ & $11.22-20.64$ & $66.02-100.25$ & $73.78-109.62$ & $70.55-105.72$ \\
& Heating 200 mg & $34.73-48.84$ & $39.00-53.64$ & $43.67-49.64$ & $18.71-32.60$ & $14.86-29.41$ & $16.28-30.59$ \\
\hline
\end{tabular}

acceptable recovery limits (USEPA, 2007). This is likely due to the reduced time for the digest leading to less $\mathrm{Hg}$ loss due to volatilization (USEPA, 2007).

We compared the efficacy of digestion methods used on hair samples for ICP-MS (As, $\mathrm{Cd}, \mathrm{Cu}$, and $\mathrm{Pb})$. The concentration of each analyte represents an average of three replicates and is reported in $\mu \mathrm{g} / \mathrm{g}$ (ppm; Tables 3 and 4). Additionally, the tables present the nominal concentrations for the CRM. Concentrations of the samples were compared to the CRM with the lower and upper uncertainties and are represented as a percent error range. Comparison of the digestion methods to the CRM demonstrated that the "overnight $20 \mathrm{mg}$ " and "heating $20 \mathrm{mg}$ " methods had better accuracy in the ICP-MS analysis than did the "overnight $200 \mathrm{mg}$ " and "heating $200 \mathrm{mg}$ " methods. The decrease in percent recovery for both the overnight $200 \mathrm{mg}$ and heating $200 \mathrm{mg}$ methods is likely attributed to incomplete digestion and would require an increase in the volume of $\mathrm{HNO}_{3}$ and $\mathrm{H}_{2} \mathrm{O}_{2}$ used. The primary difference between the overnight $20 \mathrm{mg}$ and heating $20 \mathrm{mg}$ methods was the increased recovery of

Table 4 Comparison of the three $\mathrm{Hg}$ digestion methods evaluated by CV-AAS. Average reported value in $\mu \mathrm{g} / \mathrm{g}$ is displayed at the top, followed by the true value and uncertainty, $95 \%$ con-
$\mathrm{Pb}$ from the heating method, which may be due to the concentration of $\mathrm{Pb}$ being near the detection limit of the instrument and therefore increased instability.

Except for testing different sample masses, all digestion methods were repeated in the washing experiment. Additionally, Mn was added to the ICPMS analysis as it is a contaminant of concern for our study in Yuma and many other studies elsewhere, and exposure often occurs through dust inhalation (Amir Abdul Nasir et al., 2018). Mn was not included in the initial digestion comparison experiment because it is not an analyte quantitated in the CRM. As all rodents in the study are desert animals that burrow in the soil, we expected that washing the hair would remove external contaminants. Further, the hair CRM used was prepared from washed human hair samples. Therefore, washing samples would represent a closer match between sample preparation and the CRM. We found that washing resulted in a loss in analyte concentration, except for $\mathrm{Cu}, \mathrm{Cd}$, and $\mathrm{Hg}$ (Figs. 2 and 3), revealed by ICP-MS and CV-AAS regardless of the digestion method followed. It is possible that these

\begin{tabular}{llll}
\hline Method & Heating & Overnight & Potassium permanganate \\
\hline True $(\mu \mathrm{g} / \mathrm{g})$ (uncertainty) & $0.365(0.028)$ & $0.365(0.028)$ & $0.365(0.028)$ \\
Average $(\mu \mathrm{g} / \mathrm{g})$ & 0.294 & 0.082 & 0.097 \\
Percent Error $(\%)$ & $12.9-25.3$ & $75.8-79.3$ & $71.2-75.3$ \\
\hline
\end{tabular}

fidence with coverage factor $k=2$, of the CRM. The final row is a percent error calculated by comparing the average reported value to the true value of the CRM 
metals are not major components of the soil or that rodents had metabolically deposited these metals in their hair but were not subjected to appreciable concentrations from dust.

A comparison of overnight and heating digestion method ICP-MS results revealed that for some analytes, overnight values were lower than values for heating (Fig. 3). This decrease in analyte concentration was not consistent across different analytes or even within the same sample. A possible explanation for these inconsistencies is the amount of concentrated $\mathrm{H}_{2} \mathrm{O}_{2}$ used during the digestion. $\mathrm{H}_{2} \mathrm{O}_{2}$ is commonly used in digestions and ICP-MS applications and is known to effect signal fidelity (Muller et al., 2016; Pappas, 2012). Between the overnight and heating approaches, there was a $12 \mathrm{~h}$ difference in time that could allow the $\mathrm{H}_{2} \mathrm{O}_{2}$ to off-gas in the overnight samples compared to the heating samples. This could decrease the impact of $\mathrm{H}_{2} \mathrm{O}_{2}$ on signal fidelity and, ultimately, analyte concentration.

The current methods were selected based on their simplicity and similarity to those used in prior studies of environment samples (e.g., soil and plants) (EPA, 2007b; Shin et al., 2019). Other sample preparation and digestion methods may result in higher accuracy for analyses of metal(loid)s in both human and animal hair. Methods were only evaluated with samples of rodent hair; similar experiments should evaluate the efficacy of these methods for the analysis of human hair to determine ideal approaches for human exposure and health studies. We expect such a study would reveal similar patterns to those seen in the analysis of rodent hair.

\section{Conclusions}

Hair washing impacted analyte concentrations as revealed by ICP-MS, notably decreasing their concentrations compared to unwashed samples. This was expected because the purpose of washing is to remove exogenous contaminants. While there are other variables that may influence the concentration of analytes in rodent hair (e.g., age of animal and length of exposure), the purpose of this study was to evaluate published literature and develop a consistent protocol that can be used for a larger study. Of the methods investigated for both ICPMS and CV-AAS, two methods proved suitable for
ICP-MS and one for CV-AAS. Although both overnight $20 \mathrm{mg}$ and heating $20 \mathrm{mg}$ were efficacious, overnight $20 \mathrm{mg}$ has benefits due to ease of sample preparation and efficiency of handling large numbers of samples. A single heating digestion on the day of analysis (heating method) proved to be the best approach for total $\mathrm{Hg}$ quantitation, likely due to a decrease in $\mathrm{Hg}$ volatilization.

Acknowledgements We thank our community partners Campesinos Sin Fronters, the Yuma Regional Medical Center, and the Regional Center for Border Health for their assistance with fieldwork.

Author contribution Conceptualization: Frank von Hippel, Jani C. Ingram, Jonathan Credo, Amy Chandos; Formal analysis and investigation: Jonathan Credo, Amy Chandos, Camilla Checinski; Writing-original draft preparation, Jonathan Credo; Writing-review and editing: Jonathan Credo, Amy Chandos, Jani C. Ingram, Frank von Hippel, Camilla Checinski; Funding acquisition: Jani C. Ingram, Frank von Hippel; Supervision: Jani C. Ingram, Frank von Hippel.

Funding This research was funded by the Flinn Foundation, Award Numbers 2102 and 2187, the Northern Arizona University Trace Element Analysis Center and the National Cancer Institute/Partnership for Native American Cancer Prevention, Grant U54CA143925. Stipend and tuition support were provided by the University of Arizona's University Fellows Program and the Clinical Translational Sciences Ph.D. Program as well as the Northwest Portland Area Indian Health Board, Grant S06GM127164.

Data availability The datasets generated during and/or analyzed during the current study are available from the corresponding author on reasonable request.

Code availability Code availability is not applicable to this article as no code software were generated or analyzed during the current study.

\section{Declarations}

Ethics approval Rodent collection was approved by the Northern Arizona University (NAU) Institutional Animal Care and Use Committee (protocol 17-013) and the Arizona Department of Game and Fish (Licenses SP611340 \& SP639726).

Consent to participate Not applicable in the present work.

Consent for publication All the authors have read and agreed to the published version of the manuscript. All the community partners have consented to publication of the manuscript. 
Competing interests The authors declare no competing interests.

Open Access This article is licensed under a Creative Commons Attribution 4.0 International License, which permits use, sharing, adaptation, distribution and reproduction in any medium or format, as long as you give appropriate credit to the original author(s) and the source, provide a link to the Creative Commons licence, and indicate if changes were made. The images or other third party material in this article are included in the article's Creative Commons licence, unless indicated otherwise in a credit line to the material. If material is not included in the article's Creative Commons licence and your intended use is not permitted by statutory regulation or exceeds the permitted use, you will need to obtain permission directly from the copyright holder. To view a copy of this licence, visit http://creativecommons.org/licenses/by/4.0/.

\section{References}

Alavanja, M. C., Hoppin, J. A., \& Kamel, F. (2004). Health effects of chronic pesticide exposure: Cancer and neurotoxicity. Annual Review of Public Health, 25, 155-197. https:// doi.org/10.1146/annurev.publhealth.25.101802.123020

Amir Abdul Nasir, A. F., Cameron, S. F., von Hippel, F. A., Postlethwait, J., Niehaus, A. C., Blomberg, S., \& Wilson, R. S. (2018). Manganese accumulates in the brain of northern quolls (Dasyurus hallucatus) living near an active mine. Environmental Pollution, 233, 377-386. https://doi.org/10. 1016/j.envpol.2017.10.088

Appenzeller, B. M. R., Hardy, E. M., Grova, N., Chata, C., Fays, F., Briand, O., Schroeder, H., \& Duca, R. C. (2017). Hair analysis for the biomonitoring of pesticide exposure: Comparison with blood and urine in a rat model. Archives of Toxicology, 91(8), 2813-2825. https://doi.org/10.1007/ s00204-016-1910-9

Astolfi, M. L., Protano, C., Marconi, E., Massimi, L., Brunori, M., Piamonti, D., Migliara, G., Vitali, M., \& Canepari, S. (2020). A new rapid treatment of human hair for elemental determination by inductively coupled mass spectrometry. Analytical Methods, 12(14), 1906-1918. https://doi. org/10.1039/c9ay01871a

Baldi, I., Gruber, A., Rondeau, V., Lebailly, P., Brochard, P., \& Fabrigoule, C. (2011). Neurobehavioral effects of longterm exposure to pesticides: Results from the 4-year follow-up of the PHYTONER study. Occupational and Environmental Medicine, 68(2), 108-115. https://doi.org/10. 1136/oem.2009.047811

Beernaert, J., Scheirs, J., Leirs, H., Blust, R., \& Verhagen, R. (2007). Non-destructive pollution exposure assessment by means of wood mice hair. Environmental Pollution, 145(2), 443-451. https://doi.org/10.1016/j.envpol.2006.04.025

Cabral Pinto, M. M. S., Marinho-Reis, P., Almeida, A., Pinto, E., Neves, O., Inacio, M., Gerardo, B., Freitas, S., Simoes, M. R., Dinis, P. A., Diniz, L., Ferreira da Silva, E., \& Moreira, P. I. (2019). Links between cognitive status and trace element levels in hair for an environmentally exposed population: A case study in the surroundings of the estarreja industrial area. International Journal of Environmental Research and Public Health, 16(22). https://doi.org/10.3390/ijerph16224560

EPA. (2007a). Method 245.1: Determination of mercury in waters by cold vapor atomic absorption spectrometry, Washington DC, USA.

EPA. (2007b). Method 3051A (SW-846): Microwave assisted acid digestion of sediments, sludges, and oils, Revision 1. Washington, DC.

Gellein, K., Lierhagen, S., Brevik, P. S., Teigen, M., Kaur, P., Singh, T., Flaten, T. P., \& Syversen, T. (2008). Trace element profiles in single strands of human hair determined by HR-ICP-MS. Biological Trace Element Research, 123(1-3), 250-260. https://doi.org/10.1007/ s12011-008-8104-0

Ishak, I., Rosli, F. D., Mohamed, J., \& Ismail, M. F. M. (2015). Comparison of digestion methods for the determination of trace elements and heavy metals in human hair and nails. The Malaysian Journal of Medical Sciences, 22(6), 11.

Jaspers, V. L. B., Covaci, A., Herzke, D., Eulaers, I., \& Eens, M. (2019). Bird feathers as a biomonitor for environmental pollutants: Prospects and pitfalls. Trends in Analytical Chemistry, 118, 223-226. https://doi.org/10.1016/j.trac. 2019.05.019

Kerna, A., \& Frisvold, G. (2014). Agriculture in Arizona's Economy.

Lettoof, D. C., Rankenburg, K., McDonald, B. J., Evans, N. J., Bateman, P. W., Aubret, F., \& Gagnon, M. M. (2021). Snake scales record environmental metal(loid) contamination. Environmental Pollution, 274, 116547. https://doi. org/10.1016/j.envpol.2021.116547

Lizardi, P. S., O’Rourke, M. K., \& Morris, R. J. (2008). The effects of organophosphate pesticide exposure on Hispanic children's cognitive and behavioral functioning. Journal of Pediatric Psychology, 33(1), 91-101. https:// doi.org/10.1093/jpepsy/jsm047

McIntosh, S. (1993). The determination of mercury at ultratrace levels using an automated amalgamation technique. Atomic Spectroscopy, 14(2), 47-49.

Muller, E. I., Souza, J. P., Muller, C. C., Muller, A. L. H., Mello, P. A., \& Bizzi, C. A. (2016). Microwave-assisted wet digestion with $\mathrm{H} 2 \mathrm{O} 2$ at high temperature and pressure using single reaction chamber for elemental determination in milk powder by ICP-OES and ICP-MS. Talanta, 156-157, 232238. https://doi.org/10.1016/j.talanta.2016.05.019

Pappas, R. S. (2012). Sample preparation problem solving for inductively coupled plasma-mass spectrometry with liquid introduction systems I. Solubility, chelation, and memory effects. Spectroscopy, 27(5), 20.

Pirrone, N., Baran, A., \& Wieczorek, J. (2013). Concentrations of heavy metals in hair as indicators of environmental pollution. E3S Web of Conferences, 1. https://doi.org/10. 1051/e3sconf/20130121005

Pozebon, D., Scheffler, G. L., \& Dressler, V. L. (2017). Elemental hair analysis: A review of procedures and applications. Analytica Chimica Acta, 992, 1-23. https://doi.org/ 10.1016/j.aca.2017.09.017

Shin, W. J., Jung, M., Ryu, J. S., Hwang, J., \& Lee, K. S. (2019). Revisited digestion methods for trace element analysis in 
human hair. Journal of Analytical Science and Technology, 11(1). https://doi.org/10.1186/s40543-019-0200-6

Sugeng, A. J., Beamer, P. I., Lutz, E. A., \& Rosales, C. B. (2013). Hazard-ranking of agricultural pesticides for chronic health effects in Yuma County, Arizona. Science of the Total Environment, 463-464, 35-41. https://doi.org/ 10.1016/j.scitotenv.2013.05.051

Underwood, W., \& Anthony, R. (2020). AVMA guidelines for the euthanasia of animals: 2020 edition. https://www. avma.org/sites/default/files/2020-01/2020-EuthanasiaFinal-1-17-20.pdf
EPA. (2007). Method 7473: Mercury in solids and solutions by thermal decomposition, amalgamation, and atomic absorption spectrophotometry. United States Environmental Protection Agency Washington DC, US.

Publisher's Note Springer Nature remains neutral with regard to jurisdictional claims in published maps and institutional affiliations. 